\title{
Neuropeptide Y Action in the Rat Hippocampal Slice: Site and Mechanism of Presynaptic Inhibition
}

\author{
William F. Colmers, Ken Lukowiak, and Quentin J. Pittman \\ Neuroscience Research Group and Department of Medical Physiology, University of Calgary, Calgary, Alberta T2N 4N1, \\ Canada
}

Neuropeptide Y (NPY), the most abundant peptide in mammalian CNS, has been shown to inhibit excitatory neurotransmission presynaptically at the stratum radiatum-CA1 synapse in the in vitro rat hippocampal slice. We examined the site and mechanism of this inhibition in a series of in vitro intra- and extracellular recordings in areas $\mathrm{CA1}$ and CA3, the source of much of the excitatory synaptic input to the CA1 neurons.

NPY's inhibitory action at the stratum radiatum-CA1 synapse was unaffected by high concentrations of the antagonists bicuculline, theophylline, or atropine, suggesting that it does not act by stimulating the release of the known presynaptic inhibitory transmitters GABA, adenosine, or ACh, respectively.

Bath application of $10^{-6}$ NPY, a concentration that strongly inhibited the stratum radiatum-CA1 synapse had no effect on CA3 neuron resting potential, input resistance or action potential amplitude, threshold, or duration. NPY also does not alter the amplitude or duration of the prolonged CA3 action potentials evoked in the presence of TTX, tetraethylammonium, and elevated external $\mathrm{Ca}^{2+}$ or those evoked in the presence of TTX and $\mathrm{Ba}^{2+}$ ions. NPY therefore does not alter the passive or active properties of the somata of the presynaptic CA3 neurons.

Neither the afferent fiber volley of the Schaffer collaterals in stratum radiatum of area CA1 nor the excitability of the CA3 terminals in CA1 was affected by NPY application. However, application of the transient $\mathrm{K}^{+}$current blocker, 4-aminopyridine (4-AP) at concentrations of 10 and $50 \mu \mathrm{M}$, completely abolished the action of $10^{-6} \mathrm{M}$ NPY on the stratum radiatum-CA1 excitatory synaptic potentials. This action of 4-AP could be reversed by reducing extracellular $\mathrm{Ca}^{2+}$ concentrations from a control level of 1.5 to $0.7 \mathrm{~mm}$ (in $10 \mu \mathrm{M}$ 4-AP) and to $0.5 \mathrm{~mm}$ (in $50 \mu \mathrm{M} \mathrm{4-AP)}$.

The evidence suggests that NPY inhibits excitatory synaptic transmission at the Schaffer collateral-CA1 synapse by acting directly at the terminal to reduce a $\mathrm{Ca}^{2+}$ influx.

\footnotetext{
Received Sept. 18, 1987; revised Mar. 7, 1988; accepted Mar. 14, 1988

We thank Ms. Laurel Franklin for her expert technical assistance. We are grateful to Dr. Brian A. MacVicar for stimulating discussions throughout this study. Supported by Medical Research Council of Canada grants to K.L. and Q.J.P. W.F.C. is an Alberta Heritage Foundation for Medical Research Fcllow; Q.J.P. is an MRC Scientist and an AHFMR Scholar.

Correspondence should be addressed to Dr. William F. Colmers, Department of Pharmacology, Faculty of Medicine, University of Alberta, 9-12 MSB, Edmonton, Alberta T6G 2H7, Canada

Copyright (C) 1988 Society for Neuroscience $0270-6474 / 88 / 103827-11 \$ 02.00 / 0$
}

The 36 amino acid peptide, neuropeptide Y (NPY), isolated from porcine CNS by Tatemoto in 1982, is the most abundant peptide yet described in the brain (Chronwall et al., 1985). NPY is distributed widely through the CNS and PNS of mammals (O'Donohue et al., 1985). NPY has been shown to be present within neurons of the hippocampus (Kohler et al., 1986) and to bind specifically and with high affinity to structures in the hippocampus (Martel et al., 1986). Recent studies from our laboratory have examined the effect of NPY on synaptic transmission in the mammalian CNS, using the in vitro rat hippocampal slice preparation. Bath application of NPY reduced the amplitude of the population spike (p.s.), evoked orthodromically in area CA1 of the hippocampus by stimulation of stratum radiatum, in a reversible, concentration-dependent manner (Colmers et al., 1985; Haas et al., 1987). A subsequent study (Colmers et al., 1987) showed that the mechanism of this effect was a reduction in the amplitude of the excitatory postsynaptic potential (EPSP) elicited in the CA1 pyramidal neurons by the stimulus. Bccausc no postsynaptic site of action could be demonstrated, this study strongly suggested that NPY presynaptically inhibited this EPSP.

There are several sites presynaptic to the hippocampal CA1 pyramidal neurons at which NPY might act. The synaptic terminals themselves or the axons or somata that give rise to these terminals (predominantly the CA3 pyramidal neurons and their axons, the Schaffer collaterals; Swanson et al., 1978) may possess NPY receptors. The peptide could act directly at these, possibly by altering the excitability of the terminals, axons, or cell bodies, or by altering the calcium influx at the terminals, their axons, or somata. NPY could also act indirectly, via receptors on inhibitory interneurons, which would then release inhibitory transmitters, such as GABA (Simmonds, 1984; Davidoff and Hackman, 1985), ACh (Hounsgaard, 1978; Valentino and Dingledine, 1980), or adenosine (Dunwiddie, 1980; Dunwiddie et al., 1984) to reduce the excitability or stimulus-secretion coupling mechanisms of the terminals.

This study was designed to elucidate the site and mechanism of NPY's inhibitory action on the stratum radiatum-CA1 excitatory synapse. The results suggest that NPY acts directly on the synaptic terminals and may inhibit excitatory synaptic transmission by modulating a calcium influx at the terminals.

\section{Materials and Methods}

Transverse slices of hippocampus, 350-450 $\mu \mathrm{m}$ thick, taken from 75$200 \mathrm{gm}$ male Sprague-Dawley rats, were prepared as described previously (Colmers et al., 1987). Slices were suspended on nylon mesh in a Plexiglas recording chamber. Temperature was maintained at $32 \pm$ $0.2^{\circ} \mathrm{C}$. Slices were perfused over both surfaces at a constant rate of between 2 and $3 \mathrm{ml} / \mathrm{min}$ with artificial cerebrospinal fluid (ACSF), 

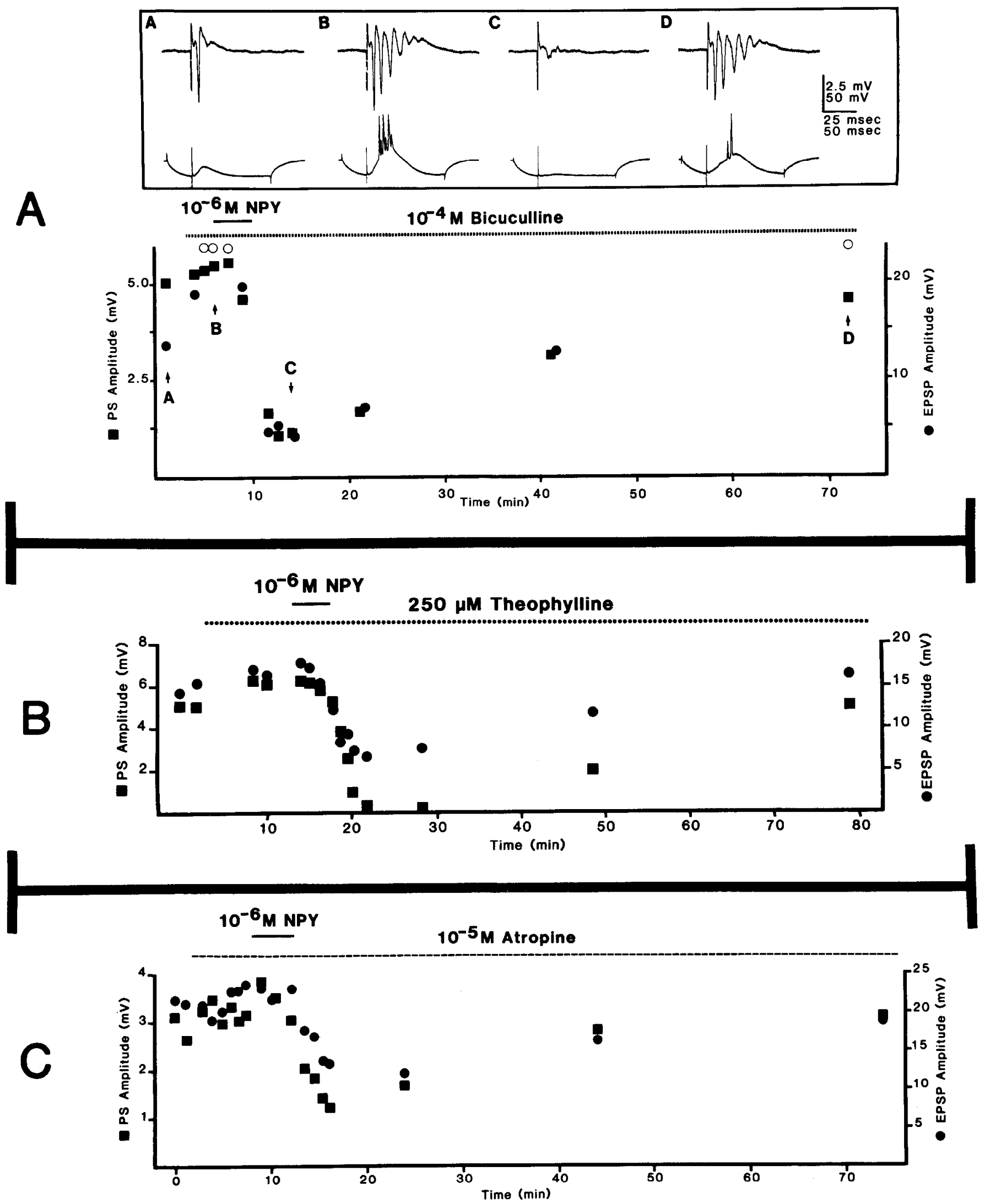

Figure 1. NPY inhibits excitatory transmission at the stratum radiatum-CA1 synapse in the presence of antagonists to receptors for known presynaptic inhibitory neurotransmitters. $A$, Effect of NPY in the presence of $10^{-4} \mathrm{M}$ bicuculline methiodide, an antagonist for GABA $\mathrm{A}_{\mathrm{A}}$ receptors. Upper panel, Extracellular (upper traces) and intracellular (lower traces) recordings from the cell body layer and pyramidal neurons of CAl, respectively, at times corresponding to those shown by letters on lower panel. Each trace is the average of 3 consecutive responses, 10 sec apart, in response to stimulation of stratum radiatum. Lower panel, Amplitude of the extracellularly recorded population spike (p.s.; left-hand vertical axis; solid circles) and excitatory postsynaptic potential (EPSP; right-hand vertical axis; solid squares) plotted against time. After control data were 
whose $\mathrm{pH}$ and oxygen tension was maintained by continuous bubbling with a gas mixture of $95 \% \mathrm{O}_{2}, 5 \% \mathrm{CO}_{2}$. ACSF composition was (in mM): $\mathrm{NaCl}, 124 ; \mathrm{NaHCO}_{3}, 26 ; \mathrm{MgSO}_{4}, 2 ; \mathrm{KCl}, 1.8 ; \mathrm{CaCl}_{2}, 1.5 ; \mathrm{KH}_{2} \mathrm{PO}_{4}, 1.25$. For experiments where $\mathrm{Ca}^{2+}$-dependent action potentials were studied, $1 \mu \mathrm{M}$ TTX, to block the transient $\mathrm{NA}^{+}$-current action potential, and 5 mM tetraethylammonium chloride (TEA), to block $\mathrm{K}^{+}$currents and thus to enhance action potential duration, were added to the perfusate. In some experiments, $2 \mathrm{mM} \mathrm{BaCl}$ was added to the ACSF, from which the $\mathrm{SO}_{4}{ }^{2-}$ and $\mathrm{PO}_{4}{ }^{2-}$ were omitted and $\mathrm{MgCl}_{2}$ substituted, in order to avoid precipitation of barium salts. TTX, $1 \mu \mathrm{M}$, was added to this medium. Bicuculline methiodide, 1,3-dimethylxanthine (theophylline), atropine sulfate, tetraethylammonium chloride (TEA), 4-aminopyridine (4-AP), TTX, and $\mathrm{BaCl}_{2}$ were obtained from Sigma (St. Louis); all other salts were obtained from Fisher Scientific (Fair Lawn, NJ).

Electrophysiological recordings. Intracellular and extracellular recordings were performed as described previously (Colmers et al., 1987). Briefly, microelectrodes containing $2 \mathrm{~m}$ potassium acetate, having resistances of 90-180 M 2 , and connected to a Dagan model 8100 amplifier used in the bridge current-clamp mode were lowered into the cell body layer of the slice. Pyramidal neurons were impaled and identified using standard electrophysiological criteria (Colmers et al., 1987). Neurons were selected whose resting membrane potential was stable at more negative than $-50 \mathrm{mV}$ for more than $20 \mathrm{~min}$; to ensure stability, experimental manipulations were generally not initiated until $30 \mathrm{~min}$ after a neuron was impaled. Hyperpolarizing current pulses of different amplitudes, injected via the current-clamp bridge circuit of the amplifier, were used to enhance EPSP amplitude and to prevent neurons from reaching action potential threshold during orthodromic synaptic stimulation. Families of hyper- and depolarizing current pulses were used for estimation of input resistance, while depolarizing current pulses were used to evoke action potentials. Extracellular recordings were made with microelectrodes containing $2 \mathrm{M} \mathrm{NaCl}$, with resistances of 2-6 Ms, which were lowered into the cell body layer or dendritic layer until a maximum field potential response to a given stimulus was recorded.

Orthodromic and antidromic stimuli were provided by means of bipolar nichrome wire stimulating electrodes, using square-wave, monophasic pulses $(100 \mu \mathrm{sec})$ supplied either by a constant-voltage stimulus isolation unit (Digitimer DS2, 2-25 V) or by a constant-current stimulus isolation unit (WPI 850,0.1-3.5 mA). The stimulating electrode was placed on stratum radiatum, either near the CA2 or CA3 boundary to evoke orthodromic synaptic potentials in area CA1 or near the middle of area CA1 to evoke antidromic potentials in area CA3. Stimuli were presented at 0.1 IIz. For experiments in which the stratum radiatumCA1 EPSP was studied, stimulus amplitude was varied between near threshold for a response to the maximum amplitude possible without the neuron achieving action potential threshold. For experiments in which the $\mathrm{CA} 3$ field potential response to antidromic stimuli was examined, stimulus amplitude was varied between threshold for the response and a maximum within the relatively linear portion of the stimulus-response relationship. For experiments in which the threshold for antidromic action potential invasion of a CA3 pyramidal neuron's soma was studied, stimulus strength was set to elicit an antidromic action potential approximately $50 \%$ of the time.

Once control responses were stable, synthetic porcine NPY (purchased either from Bachem, Torrance, CA, or the I.A.F., Montreal, Quebec, Canada, or kindly supplied to us by Dr. S. St-Pierre, Montreal), previously dissolved in ACSF or distilled water at a concentration of $10^{-1}$ $\mathbf{M}$ and stored in aliquots at $-70^{\circ} \mathrm{C}$ until just prior to use, was diluted to a final concentration of $10^{-6} \mathrm{M}$ in the appropriate ACSF. Ten milliliters of the peptide-containing ACSF was applied through the bath via a switching valve at the same flow rate as the control solution. The peptide was washed out with the control ACSF.

Data were collected and analyzed as described previously (Colmers et al., 1987). A Nicolet 4094 digital oscilloscope was used for current and voltage measurements, and to a verage signals. Data were stored either on floppy diskettes or on FM tape (Racal 4 DS). A DC-coupled pen recorder (Gould 2200S) displayed a continuous record of cell membrane potential and injected currents.

Neurons were used as their own controls for statistical purposes. Numerical data are presented as means \pm SEM. Statistical comparisons were performed using a Student's paired $t$ test, unless otherwise noted. Neuron input resistance was calculated from the slope of a least-squares regression line fitted to the data. Slope resistance data were compared using an $F$ test for comparing slopes of regression lines (Sokal and Rohlf, 1981). All data presented are from preparations monitored for at least $30 \mathrm{~min}$ after washout was initiated.

\section{Results}

The results were based on recordings from $26 \mathrm{CA} 3$ pyramidal neurons and $22 \mathrm{CA} 1$ pyramidal neurons from 41 separate preparations, under different experimental conditions. Intracellular and extracellular recordings in area CA1 were performed as described previously (Colmers et al., 1987).

\section{Indirect action}

Three neurotransmitters endogenous to the hippocampus, GABA (Storm-Mathiscn, 1977), adcnosinc (Braas ct al., 1986), and ACh (Hounsgaard, 1978; Valentino and Dingledine, 1980) are known to have presynaptic inhibitory actions in mammalian CNS excitatory pathways (Ginsborg and Hirst, 1972; Hounsgaard, 1978; Dunwiddie and Hoffer, 1980; Valentino and Dingledine, 1980; Davidoff and Hackman, 1985). To test the possibility that the observed effects of NPY on the stratum radiatumCA1 synapse were due to enhanced release of other, endogenous transmitter substances which, in turn, presynaptically inhibit transmitter release at the stratum radiatum-CAl synapse, the action of NPY was examined following blockade of the receptors mediating the presynaptic inhibition by these substances.

\section{$G A B A_{A}$ receptors}

In the first series of experiments, we studied the effect of NPY on the stratum radiatum-CA1 synapse in the presence of a high concentration $\left(10^{-4} \mathrm{M}\right)$ of the $\mathrm{G} \Lambda \mathrm{B} \Lambda_{\mathrm{A}}$ receptor blocker bicuculline (Fig. 1A). The amplitude of the extracellularly recorded p.s. (Fig. $1 A$, upper panel, upper trace) and (in several experiments) intracellularly recorded EPSP (Fig. $1 A$, upper panel, lower trace), evoked by stratum radiatum stimulation, were recorded simultaneously (Colmers et al., 1987). After control data were taken (Fig. $1 A, A$ ), ACSF containing $10^{-4} \mathrm{M}$ bicuculline was applied to the slice, which rapidly became disinhibited, demonstrating multiple p.s.'s in response to the stimulus and a greatly enhanced EPSP, which often exceeded action potential threshold (Fig. $1 A, B$ and lower panel). Application of $10^{-6} \mathrm{M}$ NPY in the presence of bicuculline rapidly reduced the amplitudes of both p.s. and EPSP (Fig. $1 A, C$ and lower panel). Subsequent washout of NPY allowed both p.s. and EPSP to return to near pre-NPY values (Fig. $1 A, D$ and lower panel). Similar results were obtained to 6 further experiments. The p.s. was

gathered $(A), 10^{-4} \mathrm{M}$ bicuculline in ACSF was applied (dotted line), and the response allowed to stabilize (B). The p.s. response became larger, and multiple p.s.'s appeared; the EPSP became greater in amplitude and exceeded action potential threshold (open circles). Application of $10^{-6} \mathrm{M}$ NPY in the presence of bicuculline caused a profound inhibition of the p.s. and EPSP $(C)$, which gradually recovered to near pre-NPY values after 1 hr washout with bicuculline ACSF $(D)$. B, Time course of an experiment similar to that in $A$, testing the effect of NPY in the presence of $250 \mu \mathrm{M}$ theophylline (dotted line), an adenosine receptor antagonist. NPY, $10^{-6} \mathrm{M}$, strongly inhibited both p.s. and EPSP with theophylline present. Both measures recovered upon subsequent washout of the peptide. $C$. Time course of an experiment similar to those above, testing NPY's effect in the presence of $10^{-5} \mathrm{M}$ atropine (dashed line), an antagonist of muscarinic cholinergic receptors. As in the above experiments, the antagonist did not interfere with the inhibitory action of NPY at the stratum radiatum-CA1 excitatory synapse. 
reduced, in the presence of NPY, to $47.0 \pm 9.0 \%$ of its preNPY value ( $p<0.001, n=7)$; the EPSP was reduced to 42.0 $\pm 2.0 \%(p<0.001, n=3)$.

\section{Adenosine}

A similar experimental design was used to test the effects of the adenosine receptor blocker theophylline on the action of NPY at the stratum radiatum-CA1 synapse (Fig. $1 B$ ). Application of $250 \mu \mathrm{M}$ theophylline to the slice (a concentration shown to be effective in blocking the adenosine $A_{1}$ receptors responsible for presynaptic inhibition; Dunwiddie et al., 1984) increased both p.s. and EPSP amplitudes; application of $10^{-6} \mathrm{M}$ NPY in the presence of theophylline reduced the p.s. to $13 \pm 1 \%$ and the EPSP to $57 \pm 7 \%$ of their values just prior to NPY application $(p<0.001, n=3)$. As before, washout returned the values to near pre-NPY values. Experiments conducted at a higher theophylline concentration (1 $\mathrm{mm}$ ) also failed to prevent the inhibitory effect of NPY.

\section{Acetylcholine}

In a third series of experiments, we examined whether NPY might be acting via the release of $\mathrm{ACh}$, which has a presynaptic inhibitory effect via a muscarinic mechanism, in addition to its other, postsynaptic excitatory action (Hounsgaard, 1978; Valentino and Dingledine, 1980). Application of a high concentration of the muscarinic cholinergic blocker atropine $\left(10^{-5} \mathrm{M}\right)$ to the slice caused a slight enhancement of EPSP and p.s. amplitudes. Application of $10^{-6} \mathrm{M}$ NPY in the presence of atropine (Fig. $1 C$ ) again caused a reduction in amplitude of the p.s. to $54 \pm 8 \%$ and of the EPSP to $57 \pm 11 \%$ of pre-NPY values ( $p$ $<0.001, n=3)$. Washout reversed NPY's effects on both measures (Fig. 1C).

\section{Direct action}

CA3 somata. To examine whether NPY inhibited synaptic transmission at the Schaffer collateral-CA1 synapse by mechanisms detectable at the soma of the presynaptic neurons, intracellular recordings were made from the somata of CA3 pyramidal cells. Neurons met the following criteria: resting membrane potential more negative than $-55 \mathrm{mV}$ (average: $-63.7 \pm 1.15 \mathrm{mV}, n=12$ ), input resistance of greater than 20 $\mathrm{M} \Omega$ (average: $67.4 \pm 6.90 \mathrm{M} \Omega, n=12$ ), action potential amplitude of $>70 \mathrm{mV}$ (average: $85.64 \pm 3.14 \mathrm{mV}, n=13$ ), and action potential duration, measured at the half-amplitude of the first action potential evoked by a depolarizing current pulse, $<1.20 \mathrm{msec}$ (average: $0.85 \pm 0.037 \mathrm{msec}, n=13$ ). These compare favorably with values obtained for these neurons by others (Brown et al., 1981; Turner and Schwartzkroin, 1984).

The bath application of $10^{-6} \mathrm{M}$ NPY did not significantly alter any of the above active and passive properties of the CA3 pyramidal neurons, based upon paired statistical comparisons of each neuron's properties before and during the period of NPY's greatest effects on the stratum radiatum-CA1 synapse. The resting membrane potential ( $p>0.50, n=18$; Fig. $2 A)$, slope input resistance $(p>0.50, n=19$; Fig. $2 B$ and $C$ ), action potential amplitude $(p>0.5, n=19)$, action potential overshoot ( $p>$ $0.5, n=19)$, and action potential duration $(p>0.5, n=19)$ were all unaffected by the application of NPY to the preparation. In addition, the number of action potentials evoked by identical current pulses and the initial membrane voltage trajectories in response to the depolarizing current pulses were unaffected by the peptide.
Of 19 CA3 neurons recorded, 11 demonstrated spontaneous action potential discharge activity. Spontaneous discharge activity varied from 1 to over 100 action potentials per minute, with an average rate of $16.7 \pm 7.4 / \mathrm{min}$. Bath application of $10^{-6} \mathrm{M}$ NPY had no significant effect on the rate of spontaneous discharge of these neurons (average: $14.27 \pm 6.24, p>0.25, n$ $=11$; Fig. 2A).

$\mathrm{Ca}^{2+}$ spikes. The possibility remained that NPY might act by interfering with a calcium influx at the terminals, thus reducing transmitter release. Because such an action might have only a small effect at the electrically distant cell body, we sought to isolate and enhance these $\mathrm{Ca}^{2+}$ influxes, so these changes could be recorded at the cell soma, as has been seen in other systems (Mudge et al., 1979; Klein et al., 1980; Goldberg et al., 1987). Two experimental approaches were employed to enhance calcium influx into neurons.

In the first series of experiments, CA3 ncurons wcre impaled, then perfused with ACSF containing $1 \mu \mathrm{M}$ TTX, to block the $\mathrm{Na}^{+}$-dependent action potential, and $5 \mathrm{~mm}$ TEA, to inhibit the time- and voltage-dependent $\mathrm{K}^{+}$currents causing repolarization (e.g., Llinás and Yarom, 1981). The concentration of $\mathrm{Ca}^{2+}$ was also increased to $4 \mathrm{~mm}$. Under these conditions, the duration of the action potential, measured at $50 \%$ repolarization, increased from $0.8-1.0 \mathrm{msec}$ to $>40 \mathrm{msec}$. The resulting pronounced plateau phase of the action potential made comparisons of its duration at $66 \%$ repolarization a more consistent measure than at $50 \%$ repolarization. Application of $10^{-6} \mathrm{M}$ NPY to the preparation did not result in any decrease in action potential duration in any of the experiments $(p>0.25, n=3$, Student's $t$ test for difference in population means).

The second approach was to further enhance calcium currents by adding $\mathrm{Ba}^{2+}$ ions to a bathing medium that contained TTX but no TEA. Since $\mathrm{Ba}^{2+}$ ions are more permeable in most $\mathrm{Ca}^{2+}$ channels than are $\mathrm{Ca}^{2+}$ ions, and slow channel inactivation (McClesky et al., 1986), the resulting action potentials were of considerably longer duration than the $\mathrm{Ca}^{2+}$ action potentials, sometimes not repolarizing for over $1 \mathrm{sec}$ (Fig. $3 A$ ). The $\mathrm{Ba}^{2+}$ action potentials often had multiple peaks separated by partial repolarizations, which then often settled into a relatively long plateau potential before repolarizing completely (Fig. $3 A$ ). The resting potential would often become unstable in the presence of barium, with large hyperpolarizations and depolarizations occurring if current was not passed to counteract them. Because the duration of the action potential has been reported to be sensitive to the resting potential (McBurney and Neering, 1985; Dolphin et al., 1986), care was taken to ensure that the resting potential remained relatively constant during the experiment. Subsequent analysis showed that there was no significant relationship between the action potential duration and resting potential within the range encountered during the experiment. Despite this, the duration of the action potential was quite variable under control conditions (Fig. $3 B$ ). Application of $10^{-6} \mathrm{M}$ NPY to these neurons caused no significant alteration in the duration of the action potential ( $p>0.5, n=3$ ).

CA3 axons. As NPY had no detectable effects on the passive or active properties of the CA3 somata, we next examined whether the peptide affected the excitability of the axons of CA3 neurons, the Schaffer collaterals. An extracellular microelectrode, placed in stratum radiatum of area CAl was used to record the field potential evoked by orthodromic stimulation of stratum radiatum. The first component of the field potential after the stimulus artifact is the afferent volley, representing the 

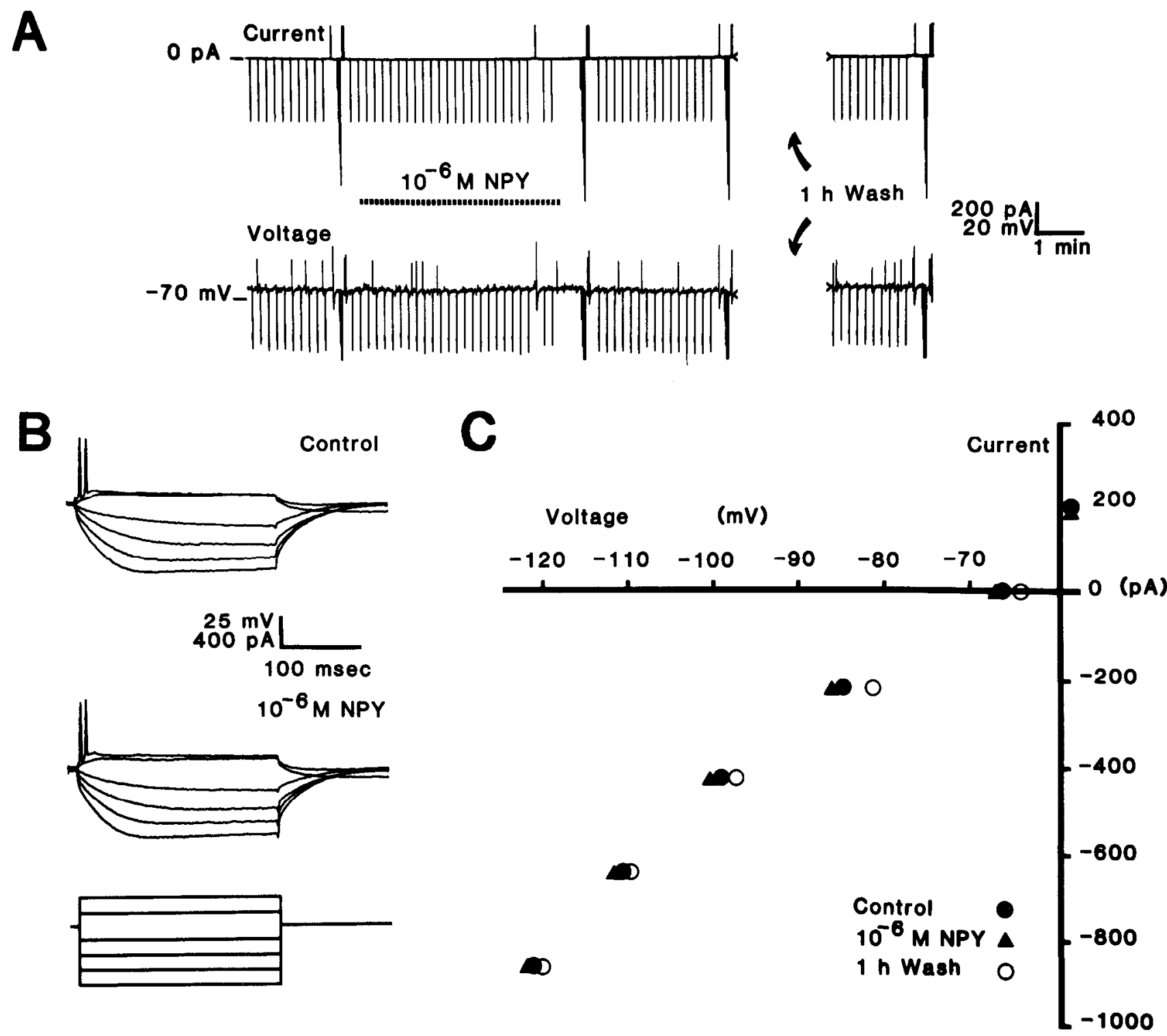

Figure 2. Summary of a typical experiment designed to test possible effects of NPY on the intracellularly recorded properties of a CA3 pyramidal neuron of rat hippocampal slice. A, Upper trace: Intracellular current passed through the bridge circuit of the current-clamp amplifier. Downward deflections indicate passage of hyperpolarizing current through the electrode. Lower trace: Intracellular voltage. NPY was bath-applied at $10^{-6} \mathrm{M}$ during the time indicated by the horizontal bar. Washout with control ACSF began immediately after NPY application ended. Note absence of effect by NPY on resting potential. $B$, Oscilloscope traces of changes in membrane potential of CA3 neuron in response to hyperpolarizing and depolarizing current pulses (lower trace) in control (upper trace) and after application of $10^{-6} \mathrm{M}$ NPY (middle trace). C, Plot of current-voltage relationship derived from records in $B$ illustrating absence of effect of NPY on membrane input resistance of neuron. Symbols: control, ${ }^{-}{ }^{-6} \mathbf{M}$ NPY, $\triangle, 1$ hr washout, $O($ not shown in $B)$.

discharge of the afferent axons (Fig. 4); the larger, slower component being the population EPSP, upon which inverted, attenuated p.s.'s are superimposed (Andersen et al., 1978). Application of $10^{-6} \mathrm{M}$ NPY to this preparation did not affect the amplitude of the afferent volley, although the population EPSP and p.s. were both reversibly attenuated by the peptide (Fig. 4). The results of this experiment were confirmed in others in which a clear afferent volley was also discernible $(p>0.5, n=3)$.

CA3 terminals. Because neither the axons nor the cell bodies of the CA3 pyramidal neurons appear to be affected by application of concentrations of NPY which produced strong inhibition of both EPSP and p.s. in area CA1 (Colmers et al., 1985, 1987), we next examined whether NPY altered the excitability of the terminals of the CA3 neurons. Two experimental ap- proaches were used. In the first, CA3 neurons were impaled and stimulated antidromically from stratum radiatum of area CA1, where their axons terminate on the apical dendrites of the CA1 pyramidal cells (Swanson et al., 1978). Action potentials were considered antidromic if they demonstrated constant latency, were initiated suddenly, rather than subsequent to a slower depolarization, and followed high-frequency stimuli (Fig. 5B). Spontaneously active neurons often demonstrated collision cancellation as well (Fig. 5B2). A slow depolarizing potential, which occasionally caused the neuron to achieve threshold (Fig. 5B2), often followed the initial antidromic action potential; this was judged to be synaptic in origin (see below). Care was taken to set stimulus strength so that antidromic action potentials were evoked by approximately $50 \%$ of the stimuli. NPY was then 

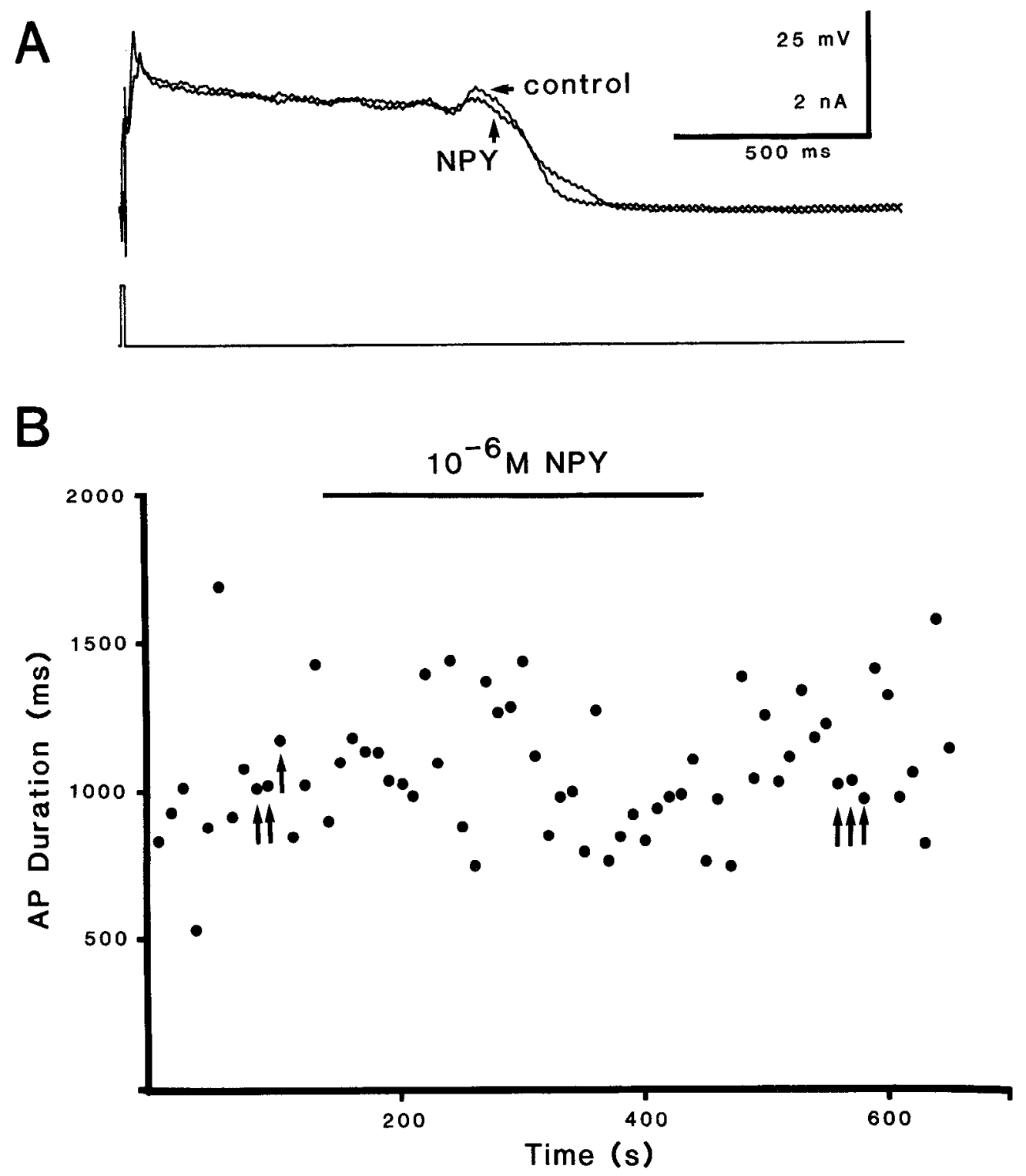

Figure 3. $\mathrm{Ba}^{2+}-$ dependent action potentials in CA3 pyramidal neuron. $\mathrm{Na}^{+}-$ dependent potentials were prevented by application of $10^{-6} \mathrm{M}$ TTX prior to NPY application. $A$, Shown superimposed are the averages of 3 successive action potentials each in control and in $10^{-6} \mathrm{M}$ NPY (arrows in $B$ ). $B$, Duration of $\mathrm{Ba}^{2+}$ dependent action potentials of $\mathrm{CA} 3$ pyramidal neuron in $A$ plotted against time. Average duration was $1.066 \pm$ $0.044 \sec (n=20)$ prior to NPY application. Application of $10^{-6} \mathrm{M}$ NPY (bar) had no effect on duration (average $=$ $1.067 \pm 0.035 \mathrm{sec}, n=20, p>0.5)$.

applied and the cell monitored for changes in either the probability of antidromic action potential invasion or for a change in latency (Wall, 1958; Carpenter et al., 1963). Figure 5 illustrates the results from one such experiment. Bath application of NPY affected neither the latency (Fig. $5 C$ ) nor the probability of antidromic action potential invasion ( $p>0.5$, Student's $t$ test for difference in population means). Results from 10 NPY applications to 7 CA3 neurons were similar.

Since the antidromically evoked p.s. represents the excitation of a population of CA3 neurons from their terminals, it could provide a more sensitive index of any small changes in terminal excitability than the behavior of an individual neuron. The second experimental approach was therefore to place an extracellular microelectrode in the cell body layer of area CA3 and stimulate stratum radiatum as before. In this instancc, wc monitored the amplitude of the antidromically evoked p.s., applied NPY, and determined if there was a change in the p.s. amplitude associated with peptide application (Fig. 6).

At lower stimulus strengths, a single-component, short-latency field potential was evoked; with increasing stimulus strength, a second component emerged. The second component was most likely synaptic in origin, as it was reversibly abolished by application of ACSF containing $0.5 \mathrm{mM} \mathrm{Ca}^{2+}, 3.5 \mathrm{mM} \mathrm{Mg}^{2+}$ (Colmers et al., 1987); the first component was unaffected by this treatment and was therefore considered antidromic (Fig. 6A). This procedure was carried out with each experimental preparation in this series.

Application of $10^{-6} \mathrm{M}$ NPY to this preparation did not affect the amplitude of the antidromic component of the CA3 field potential (Fig. $6 B$ ). This finding was confirmed in other experiments $(p>0.50, n=4)$. In one experiment, the stimulus strength was varied to produce a stimulus-response relationship (Fig. 6C). NPY did not significantly affect the amplitude of the antidromic population spike at any of the stimulus strengths examined. In 2 of the 4 experiments, the synaptic component of the field potential was reversibly attenuated by NPY. The reduction was not as dramatic as was seen in area CA1 (Colmers et al., 1985).

Although NPY did not measurably alter the excitability of the CA3 terminals of stratum radiatum, the possibility remained that it could affect conductances that are not active at rest. To examine this, we studied the effect of NPY on the stratum ra- 


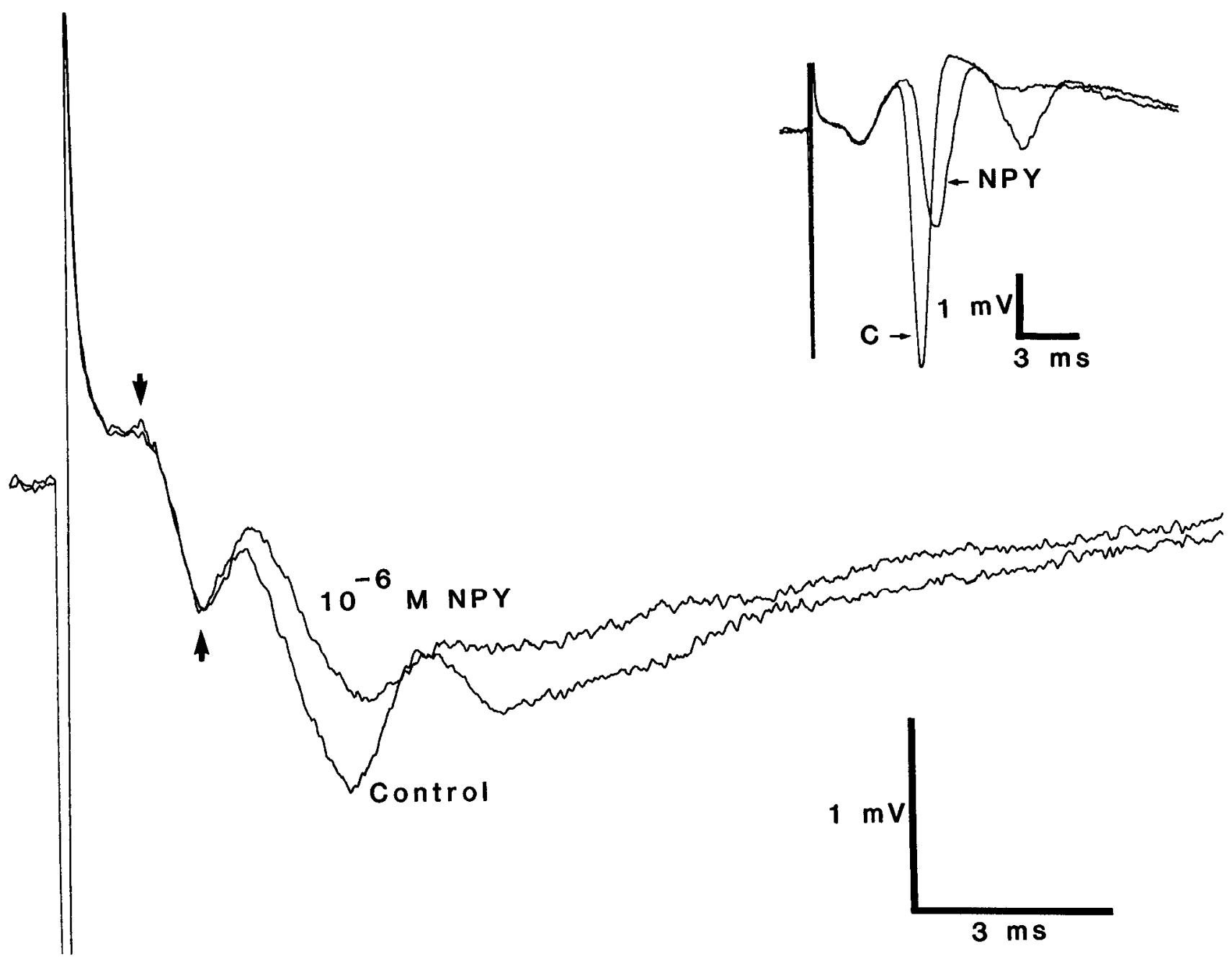

Figure 4. Extracellular field potential records from stratum radiatum and from cell body layer (inset) of area CA1 of rat hippocampal slice. Afferent presynaptic volley (between arrows) is the first component of the field potential recorded in stratum radiatum, representing the simultaneous discharge of afferent fibers in response to electrical stimulation of stratum radiatum; the larger, slower component of the field potential represents the population EPSP, representing the postsynaptic dendritic response of the CA1 pyramidal neurons. Superimposed on the latter portion of the population EPSP is a positive-going deflection representing the inverted p.s. (see inset). Application of $10^{-6} \mathrm{M}$ NPY did not attenuate the amplitude of the afferent volley, although it reduced the amplitude of both the population EPSP and p.s.

diatum-CAl synapse in the presence of the potassium channel blocker, 4-aminopyridine (4-AP), which is particularly effective at nerve terminal $\mathrm{K}^{+}$channels (Katz and Miledi, 1969; Buckle and Haas, 1982; Bartschat and Blaustein, 1985).

Bath application of $50 \mu \mathrm{M}$ 4-AP enhanced the amplitude and duration of evoked excitatory synaptic transmission, as others have reported (Katz and Miledi, 1969; Buckle and Haas, 1982; Fig. 7). On one occasion, spontaneous epileptiform discharges could be recorded in the extracellular field. This increase in synaptic response was not accompanied by a significant increase in the somatic input resistance of the CA1 pyramidal neurons. In the presence of $50 \mu \mathrm{M} 4-\mathrm{AP}$, application of $10^{-6} \mathrm{M}$ NPY was without effect on the p.s. (Fig. 7, top left; $n=3, p>0.5$ ) or EPSP (not illustrated; $n=3, p>0.5$ ). NPY also did not affect the spontaneous epileptiform discharges observed in the one preparation.

Application of 4-AP at the lower concentration of $10 \mu \mathrm{M}$ also enhanced evoked synaptic transmission, although to a lesser extent than at the higher concentration (Fig. 7, top right); no spontaneous discharges were observed in preparations. There was also no significant change in somatic input resistance. 4-AP, $10 \mu \mathrm{M}$, also completely abolished the inhibition normally seen with $10^{-6}$ NPY of both p.s. (Fig. 7, top right; $n=3 ; p>0.5$ ) and $\operatorname{EPSP}(n=3, p>0.5$, not illustrated).

Blockade of $\mathrm{K}^{+}$channels at the nerve terminal can delay membrane repolarization, consequently enhancing $\mathrm{Ca}^{2+}$ influx through voltage-dependent channels (Molgo et al., 1977; Buckle and Haas, 1982). If NPY were to inhibit a $\mathrm{Ca}^{2+}$ influx caused by $\mathrm{K}^{+}$ channel blockade, its action might be overwhelmed by the increased $\mathrm{Ca}^{2+}$ influx caused by $\mathrm{K}^{+}$channel blockade. To test this possibility, we therefore reduced the $\mathrm{Ca}^{2+}$ concentration in the medium to compensate for the increased influx at the terminals and then examined NPY's actions under these conditions.

In separate experiments, it was determined empirically that lowering extracellular $\mathrm{Ca}^{2+}$ to $0.7 \mathrm{~mm}$ approximately counteracted the effects of $10 \mu \mathrm{M}$ 4-AP (Fig. 7, center right), such that the p.s. and EPSP were both restored to nearly their control amplitudes and waveforms. Under these conditions, $10^{-6} \mathrm{M}$ NPY caused a long-lasting, reversible reduction in p.s. amplitude to $49.3 \pm 14.3 \%$ of control $(n=4, p<0.001 ;$ Fig. 7$)$ and 

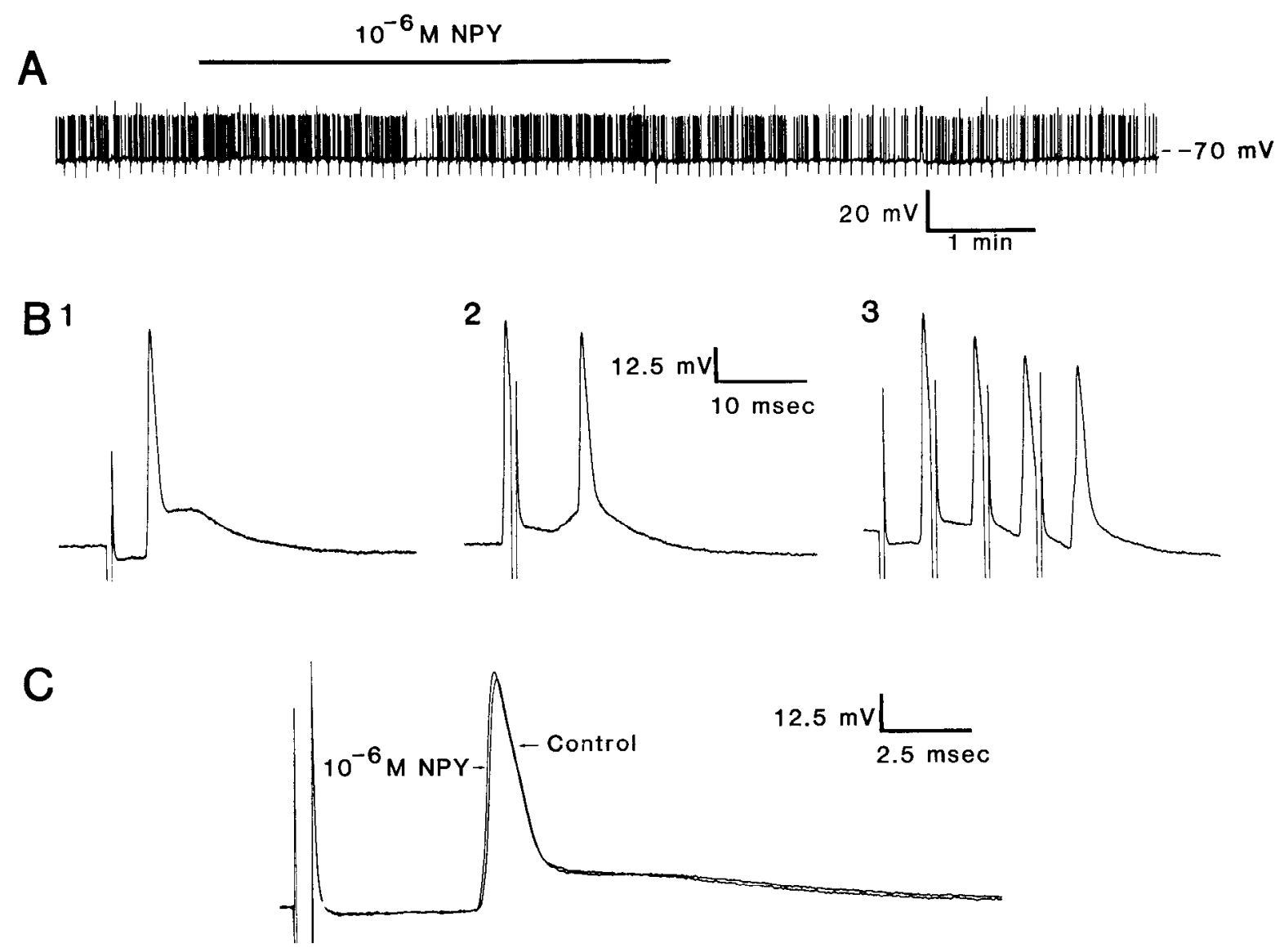

Figure 5. Antidromic activation of a CA3 pyramidal neuron from stratum radiatum of area CA1. Stimulus intensity was set to elicit an action potential in approximately $50 \%$ of the stimuli. $A$, Chart record of spontaneous activity and resting potential before, during, and after bath application of $10^{-6} \mathrm{M}$ NPY $($ bar $)$. Downward deflections represent shock artifact from stimulating electrode. NPY application had no significant efrect un spontaneous activity. $B$, Action potentials were demonstrably antidromic in origin. $l$, Action potential arises abruptly rest, followed by depolarizing potential, probably synaptic in origin. 2 , Spontaneous action potential prior to stimulus results in collision cancellation of antidromic potential; the synaptic potential than causes neuron to exceed threshold. $B$. Neuron follows antidromic stimuli with constant latency at a frequency of 200 Hz. $C$, Bath application of $10^{--6} \mathrm{M}$ NPY does not affect latency of antidromic action potential. NPY had no effect on the probability of an action potential being elicited antidromically (not shown).

in EPSP amplitude to $66.1 \pm 3.51 \%$ of control $(n=3, p<$ 0.001 ; Fig. 7). Washout of the peptide allowed recovery of both p.s. and EPSP (not illustrated).

NPY was ineffective in the presence of $50 \mu \mathrm{M} 4-\mathrm{AP}$ and 0.7 $\mathrm{mM} \mathrm{Ca}^{2+}$ (Fig. 7, center left); however, a further reduction in extracellular $\mathrm{Ca}^{2+}$ to $0.5 \mathrm{~mm}$ restored NPY's inhibitory action both on the p.s. (to $50.1 \pm 10.89 \%$ of control, $n=4, p<0.001$; Fig. 7, bottom left) and on the EPSP (to $51.4 \pm 5.06 \%$ of control, $n=3, p<0.001$; Fig. 7).

\section{Discussion}

This study confirms previous findings (Colmers et al., 1985, 1987; Haas et al., 1987) that NPY can attenuate excitatory transmission at the Schaffer collateral-CA1 synapse in hippocampus. The present evidence suggests that NPY (1) acts directly, rather than by eliciting the release of another inhibitory substance, and (2) acts at the level of the presynaptic terminal. Furthermore, the evidence here is consistent with an NPYmediated inhibition of $\mathrm{Ca}^{2+}$ influx at the presynaptic terminal.

A number of possible mechanisms for NPY's action were considered in this study. We first examined whether NPY could act indirectly by eliciting the release, from synaptic boutons near the excitatory terminals, of endogenous neurotransmitters which themselves inhibit transmitter release. Although this could not be tested in a direct way by blocking synaptic transmission, there was no evidence from indirect tests to suggest that NPY required functional $\mathrm{GABA}_{\mathrm{A}}$, adenosine $\mathrm{A}_{\mathrm{k}}$, or muscarinic cholinergic receptors for its action. Although we cannot exclude the possibility that another, yet unidentified presynaptic inhibitor of excitatory synaptic transmission is involved, we consider it most likely that NPY acts in a direct manner.

Examination of a number of possible direct mechanisms of NPY action at several sites presynaptic to the CA1 pyramidal neurons showed that NPY did not change the excitability in the cell bodies of the presynaptic neurons by decreasing the membrane input resistance or by changing the resting potential nor did it affect either the $\mathrm{Na}^{+}$- or the $\mathrm{Ca}^{2+}$-dependent components of the somatic action potential. Because the $\mathrm{Ca}^{2+}$-dependent action potential in these neurons largely involves the noninactivating, "L" type $\mathrm{Ca}^{2+}$ channel, thcsc data suggest that NPY action in hippocampus differs from that in cultured rat dorsal root ganglion neurons, where an inhibition by NPY of the L current has recently been reported (Ewald et al., 1987). These data do not exclude the possibility that, in adult hippocampal CA3 neurons, somatic $\mathrm{Ca}^{2+}$ conductances not participating in action potential generation could be affected by NPY. NPY also 
A

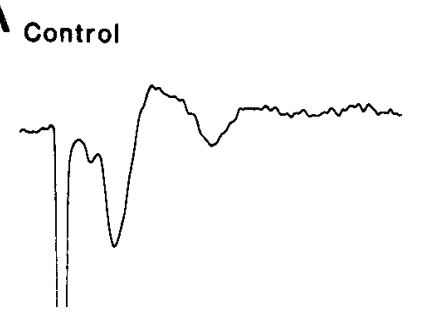

$0.5 \mathrm{mM} \mathrm{Ca}^{++} 3.5 \mathrm{mM} \mathrm{Mg}^{++}$

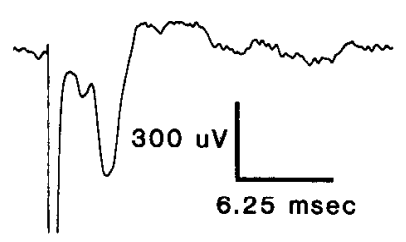

$30 \mathrm{~min}$ Wash

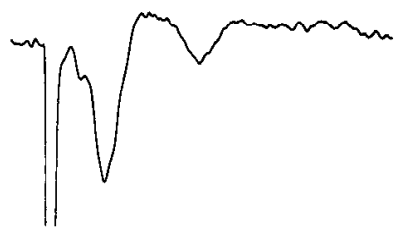

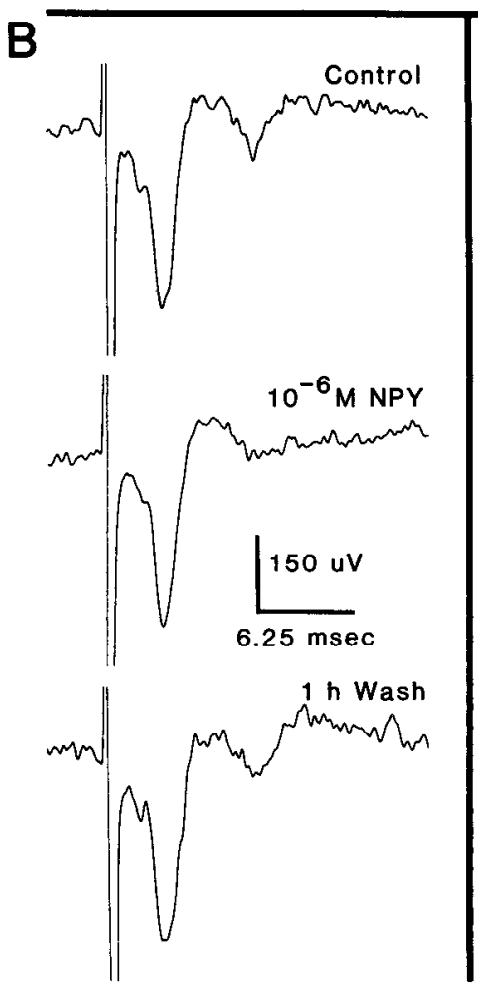

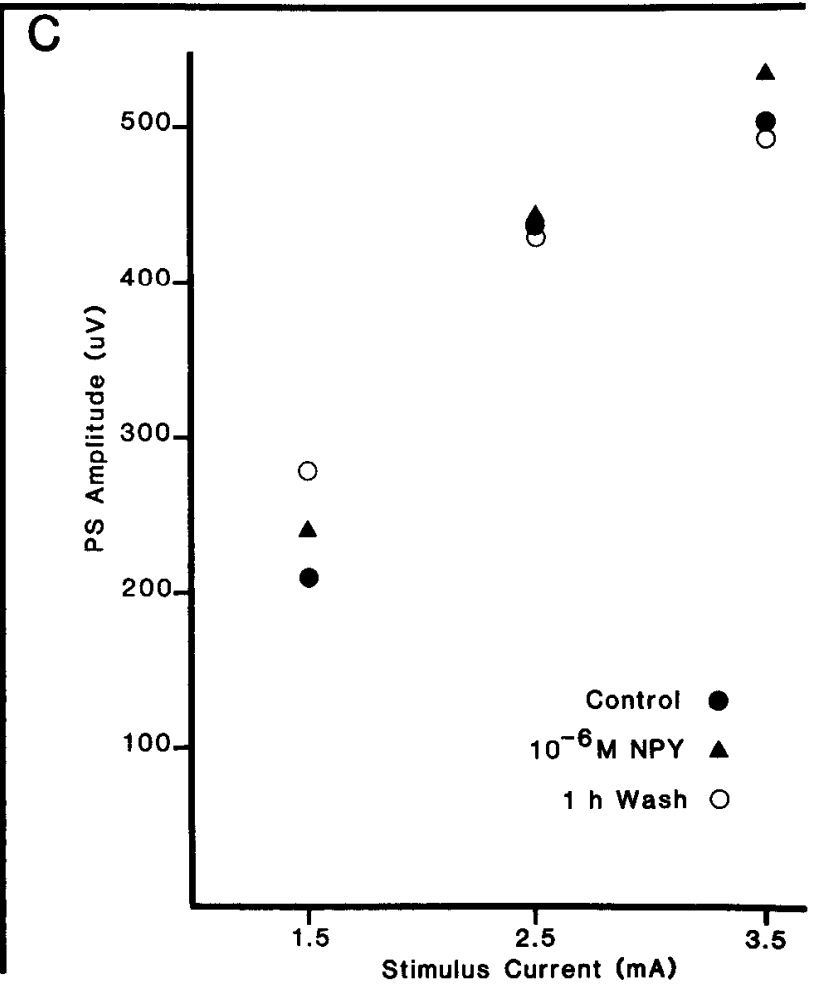

Figure 6. Extracellularly recorded ficld potential in area $\mathrm{CA} 3$ elicited by antidromic stimulation from stratum radiatum of area CA $1 . A$, First negative component of field potential after stimulus shock artifact is antidromic in origin, as it is resistant to blockade of synaptic transmission by the bath application of low-Ca ${ }^{2+}$, high- $\mathrm{Mg}^{2+} \mathrm{ACSF}$, while the second component is reversibly inhibited by this treatment. $B$, Bath application of $10^{-6} \mathrm{M}$ NPY does not attenuate antidromic population spike, while attenuating second component reversibly. $C$, Stimulus-response rclationship of antidromic component of CA3 field potential in control (๑), $10^{-6} \mathrm{M}$ NPY $(\boldsymbol{\wedge})$, and after $1 \mathrm{hr}$ washout $(\mathrm{O})$. Note absence of NPY effect at all stimulus intensities.

does not appear to reduce the excitability of the axons of the CA3 pyramids in the stratum radiatum, in agreement with the observations of Haas et al. (1987). Since the postsynaptic CA1 pyramidal neuron is also not affected by NPY (Colmers et al., 1987; Haas et al., 1987), NPY most probably acts upon the presynaptic terminals themselves.

Possible mechanisms by which NPY could affect transmitter release at the synaptic terminal include the activation or enhancement of a $\mathrm{K}^{+}$conductance. The blockade of NPY's action by low concentrations of the $\mathrm{K}^{+}$channel blocker 4-AP was consistent with the idea that NPY worked via a 4-AP-sensitive conductance. However, even in the presence of 4-AP, NPY's inhibition of the synapse could be restored by lowering the extracellular $\mathrm{Ca}^{2+}$ concentration. NPY thus does not appear to modulate a 4-AP-sensitive $\mathrm{K}^{+}$conductance. NPY could, however, activate a 4-AP-insensitive $\mathrm{K}^{+}$conductance. One of the consequences of 4-AP blockade of $\mathrm{K}^{+}$conductances is an increased input resistance at the terminal. However, an NPYmediated activation of a $\mathrm{K}^{+}$conductance under these circumstances would then be expected to lead to a greater hyperpolarization than without 4-AP; therefore, a greater, rather than a reduced, effect of NPY should have been seen. As this was not observed, we conclude that NPY probably does not activate a potassium conductance at the terminal.

The data are consistent, however, with a modulation by NPY of a $\mathrm{Ca}^{2+}$ influx at the presynaptic terminal. We reasoned that the enhanced $\mathrm{Ca}^{2+}$ influx into the terminal brought about by 4-AP's action on $\mathrm{K}^{+}$currents could overwhelm the normal inhibitory action of NPY on a $\mathrm{Ca}^{2+}$ influx. Consistent with this, after reduction of $\mathrm{Ca}^{2+}$ levels (and therefore reduction of $\mathrm{Ca}^{2+}$ influx), the action of NPY was restored. It would appear that, at this reduced extracellular $\mathrm{Ca}^{2+}$ concentrations, NPY inhibition of $\mathrm{Ca}^{2+}$ currents again becomes the major factor in the control of transmitter release. An influence of NPY on $\mathrm{Ca}^{2+}$ currents, rather than on resting $\mathrm{K}^{+}$permeabilities, would also explain our failure to observe changes in terminal excitability in the antidromic stimulation experiments.

Although NPY did not influence the $\mathrm{Ca}^{2+}$ - and $\mathrm{Ba}^{2+}$-dependent action potentials in CA3 neurons, the peptide could nonetheless act on such conductances at their terminals. Autoradiographic binding studies show that NPY receptors are not present in the cell body layers of areas CA1 or CA3 but are restricted to strata radiatum and oriens (Martel et al., 1986). If the receptors (and the effectors to which they are coupled) are not present near the soma, changes in $\mathrm{Ca}^{2+}$ influx brought about by NPY would not be expected to influence the action potential measured at the soma (e.g., Williams and Ziegelgansberger, 1981). Because the terminals of the CA3 neurons are electrotonically very remote from their somata (up to 100 length constants: D. A. Turner, personal communication), it is possible that NPY's at- 
50 HM 4-AP

Control

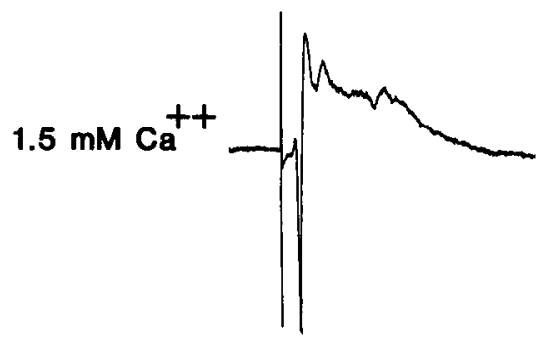

$0.7 \mathrm{mMCa}^{++}$
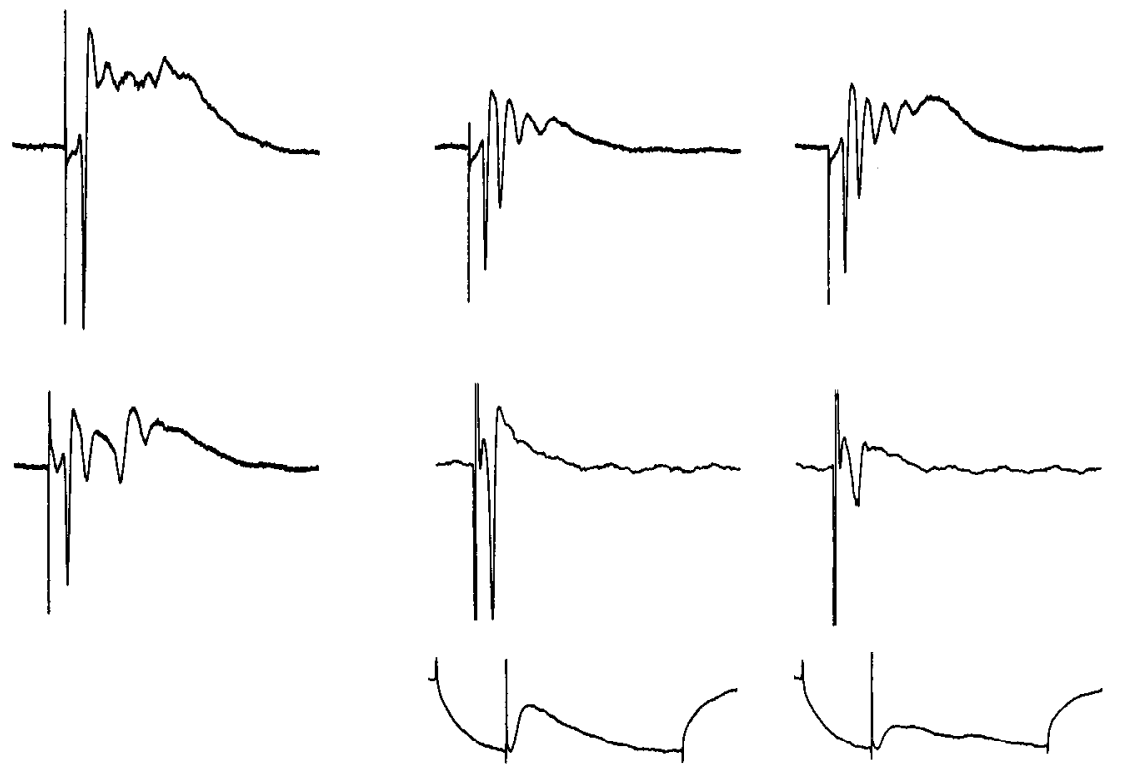

Control

$10^{-6} \mathrm{M}$ NPY

$10 \mu \mathrm{M}$ 4-AP
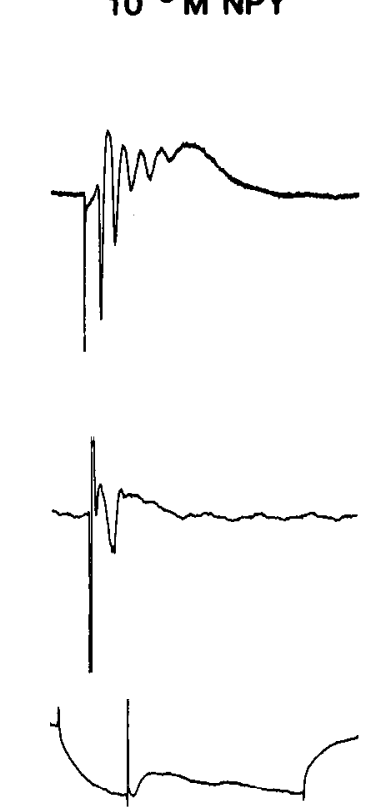
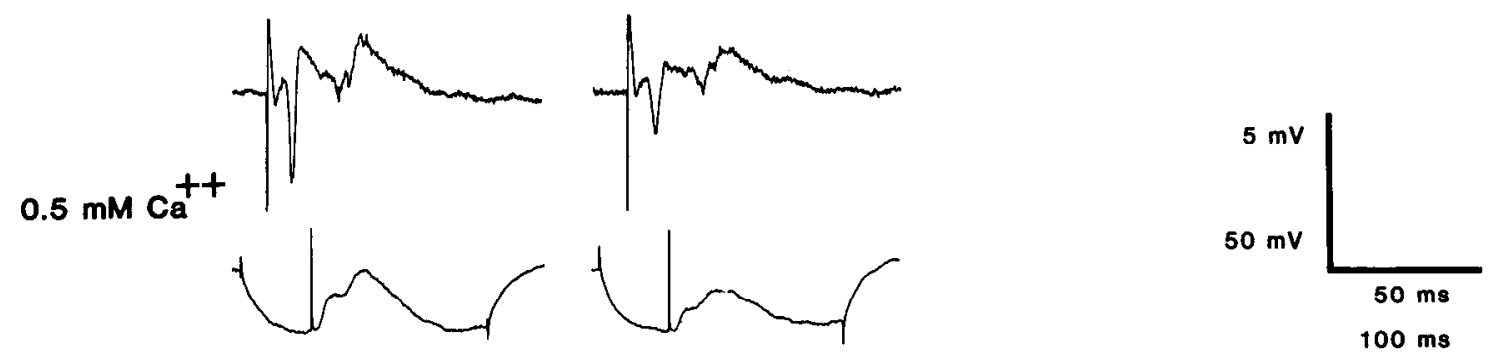

Figure 7. Effects of 4-aminopyridine (4-AP) and reduced extracellular $\mathrm{Ca}^{2+}$ concentrations on the NPY-mediated inhibition of excitatory synaptic transmission in CA1. Data for each combination shown were taken from separate preparations. Left side of figure shows action of $50 \mu \mathrm{M} 4-\mathrm{AP}$; right side, that of $10 \mu \mathrm{M}$ 4-AP. Left-hand column of each side depicts effects of 4-AP alone; right columns, effects after $10^{-6} \mathrm{M}$ NPY has been applied in the presence of 4-AP. Extracellular field potentials only are shown for combinations where NPY was without effect, intracellular records including EPSP are shown where NPY inhibited excitatory synaptic transmission. NPY inhibited synaptic transmission in $10 \mu \mathrm{M} 4-\mathrm{AP}$ with $0.7 \mathrm{mM}$ Ca ${ }^{2+}$ (center row) and in $50 \mu \mathrm{M}$ 4-AP with $0.5 \mathrm{mM} \mathrm{Ca}^{2+}$ (bottom row). NPY's inhibitory effects were reversible under these circumstances (not illustrated).

tenuation of $\mathrm{Ca}^{2+}$ influx at the terminal would not be detectable at the soma. Experiments on hippocampal neurons in culture might permit the resolution of this question, as it is possible that the receptors and effectors may be expressed sufficiently close to the soma to have a measurable influence on somatic properties (Mudge et al., 1980; Williams and Ziegelgansberger, 1981). Indeed, recent evidence from rat dorsal root ganglion cells in culture indicate that NPY does reduce their somatic $\mathrm{Ca}^{2+}$ conductances (Ewald et al., 1987).

Since we have not been able to measure $\mathrm{Ca}^{2+}$ influx into the presynaptic terminal directly or to examine the calcium sensitivity of transmitter release (Malenka et al., 1986), the present experiments do not constitute an unequivocal demonstration of NPY's mechanism of action. Nonetheless, we consider it most probable that an inhibition of $\mathrm{Ca}^{2+}$ influx at the excitatory presynaptic terminals in stratum radiation underlies the reduction in synaptic transmission caused by NPY.

\section{References}

Andersen, P., H. Silfvenius, S. H. Sundberg, O. Svecn, and H. Wigstrom (1978) Functional characteristics of unmyelinated fibres in the hippocampal cortex. Brain Res. 144: 11-18.
Bartschat, D. K., and M. P. Blaustein (1985) Potassium channels in isolated presynaptic nerve terminals from rat brain. J. Physiol. (Lond.) 361: $419-440$.

Braas, K. M., A. C. Newby, V. S. Wilson, and S. H. Snyder (1986) Adenosine-containing neurons in the brain localized by immunocytochemistry. J. Neurosci. 6: 1952-1961.

Brown, T. H., R. A. Fricke, and D. H. Perkel (1981) Passive electrical constants in three classes of hippocampal neurons. J. Neurophysiol. 41: 812-827.

Brown, T. II., R. A. Fricke, and S. H. Snyder (1986) Adenosinecontaining neurons in the brain localized by immunocytochemistry. J. Neurophysiol, 46: 812-827.

Buckle, P. J., and H. L. Haas (1982) Enhancement of synaptic transmission by 4-aminopyridine in hippocampal slices of the rat. J. Physiol. (Lond.) 326: 109-122.

Carpenter, D., A. Lundberg, and U. Norrsell (1963) Primary afferent depolarization evoked from the sensorimotor cortex. Acta Physiol. Scand. 59: 126-142.

Chronwall, B. M., D. A. Dimaggio, V. J. Massari, V. M. Pickel, D. A. Ruggiero, and T. L. O'Donohue (1985) The anatomy of neuropeptide $\mathrm{Y}$ containing neurons in the rat brain. J. Neurosci. 15: 11591181.

Colmers, W. F., K. D. Lukowiak, and Q. J. Pittman (1985) Neuropeptide $\mathrm{Y}$ reduces orthodromically evoked population spike in rat hippocampal CA1 by a possibly presynaptic mechanism. Brain Res. 346: 404-408. 
Colmers, W. F., K. D. Lukowiak, and Q. J. Pittman (1987) Presynaptic action of neuropeptide $\mathrm{Y}$ in area CAl of the rat hippocampal slice. J. Physiol. (Lond.) 383: 285-299.

Davidoff, R. A., and J, C. Hackman (1985) GABA: Presynaptic actions. In Neurotransmitter Actions in the Vertebrate Nervous System, M. A. Rogawski and J. L. Barker, eds, pp. 3-32, Plenum, New York.

Dolphin, A. C., S. R. Forda, and R. H, Scott (1986) Calcium-dependent currents in cultured rat dorsal root ganglion neurons are inhibited by an adenosine analogue. I. Physiol. (Lond.) 373: 47-61.

Dunwiddie, T. V. (1980) Interactions between the effects of adenosine and calcium on synaptic responses in rat hippocampus in vitro. $\mathrm{J}$. Physiol. (Lond.) 350: 545-559.

Dunwiddie, T. V., and B. J. Hoffer (1980) Adenine nucleotides and synaptic transmission in the in vitro rat hippocampus. Br. J. Pharmacol. 69: 59-68.

Dunwiddie, T. V., A. S. Basile, and M. R. Palmer (1984) Electrophysiological responses to adenosine analogs in rat hippocampus and cerebellum: Evidence for mediation by receptors of the $A_{1}$-subtypes. Life Sci. 34: 37-47.

Ewald, D. A., R. J. Miller, and P. C. Sternweis (1987) Involvement of C-kinase and $\mathrm{G}$ proteins in inhibition of $\mathrm{Ca}^{2+}$ currents by neuropeptide $Y$ in rat dorsal root ganglion neurons. Soc. Neurosci. Abstr. 13: 794.

Ginsborg, B. L., and G. D. S. Hirst (1972) The effect of adenosine on the release of the transmitter from the phrenic nerve of the rat. $J$. Physiol. (Lond.) 224: 629-645.

Goldberg, J. I., W. F. Colmers, J. P. Edstrom, and K. Lukowiak (1987) Suppression of sensory to motor synaptic transmission and narrowing of the sensory neuron action potential by arginine vasotocin in Aplysia californica. J. Exp. Biol. 128: 47-62.

Haas, H. L., A. Hermann, R. W. Greene, and V. Chan-Palay (1987) Action and location of neuropeptide tyrosine ( $Y$ ) on hippocampus neurons of the rat in slice preparations. J. Comp. Neurol. 257: 208215.

Hounsgaard, J. (1978) Presynaptic inhibitory action of acetylcholine in area CA1 of the hippocampus. Exp. Neurol. 62: 787-797.

Katz, B., and R. Miledi (1969) Spontaneous and evoked activity of motor nerve endings in calcium Ringer. J. Physiol. (Lond). 203: 689701.

Klein, M., E. Shapiro, and E. R. Kandel (1980) Synaptic plasticity and the modulation of the $\mathrm{Ca}^{2+}$ current. J. Exp. Biol. 89: 117-157.

Kohler, C., L. Eriksson, S. Davies, and V. Chan-Palay (1986) Neuropeptide $\mathrm{Y}$ innervation of the hippocampal region in the rat and monkey brain. J. Comp. Neurol. 244: 569-584.

Llinás, R., and Y. Yarom (1981) Properties and distribution of ionic conductances generating electroresponsiveness of mammalian inferior olive neurons in vitro. J. Physiol. (Lond.) 315: 569-584.
Malenka, R. C., D. V. Madison, and R. A. Nicoll (1986) Potentiation of synaptic transmissions in the hippocampus by phorbol esters. Nature 321: $175-177$.

Martel, J. C., S. St-Pierre, and R. Quirion (1986) Neuropeptide $Y$ receptors in rat brain: Autoradiographic localization. Peptides 7:5560.

McBurney, R. N, and I, R. Neering (1985) Relationships between action potential duration and peak change in $\left[\mathrm{Ca}^{2+}\right]_{i}$ in rat sensory neurons grown in cell culture. J. Physiol. (Lond.) 365: 59P.

McClesky, E. W., A. P. Fox, D. Feldman, and R. W. Tsien (1986) Different types of calcium channels. J. Exp. Biol. 124: 177-190.

Molgo, J., M. Lemeignan, and P. Lechat (1977) Effects of 4-aminopyridine at the frog neuromuscular junction. J. Pharmacol. Exp. Ther. 203: 653-663.

Mudge, A. W., S. E. Leeman, and D. Fischbach (1979) Enkephalin inhibits release of substance $\mathbf{P}$ from sensory neurons in culture and decreases action potential duration. Proc. Natl. Acad. Sci. USA 76: 526-530.

O'Donohue, T. L., B. M. Chronwall, R. M. Pruss, E. Mezey, J. Z. Kiss, L. E. Eiden, V. J. Massari, R. E. Tessel, V. M. Pickel, D. A. DiMaggio, A. J. Hotchkiss, W. R. Crowley, and A. Zukowska-Grojek (1985) Neuropeptide $\mathrm{Y}$ and peptide $\mathrm{YY}$ neuronal and endocrine systems. Peptides 6: 755-768.

Simmonds, M. A. (1984) Physiological and pharmacological characterization of the action of GABA. In Actions and Interactions of $G A B A$ and Benzodiazepines, N. G. Bowery, ed., pp. 27-41, Raven, New York.

Sokal, R. R., and F. J. Rohlf (1981) Biometry, 2nd ed., Freeman, San Francisco.

Storm-Mathisen, J. (1977) Localization of transmitter candidates in the brain: The hippocampal formation as a model. Prog. Neurobiol. 8: 119-181.

Swanson, L. W., J. M. Wyss, and W. M. Cowan (1978) An autoradiographic study of the intrahippocampal association pathways in the rat. J. Comp. Neurol. 181: 681-716.

Tatemoto, K. (1982) Neuropeptide Y: Complete amino acid sequence of the brain peptide. Proc. Natl. Acad. Sci. USA 79: 5485-5489.

Turner, D. A., and P. A. Schwartzkroin (1984) Passive electrotonic structure and dendritic properties of hippocampal neurons. In Brain Slices, R. Dingledine, ed., pp. 25-50, Plenum, New York.

Valentino, R. J., and R. Dingledine (1980) Presynaptic inhibitory effect of acetylcholine in the hippocampus. J. Neurosci. 1: 784-792.

Wall, P. D. (1958) Excitability changes in afferent fibrc terminations and their relation to slow potentials. J. Physiol. (Lond.) 142: 1-21.

Williams, J., and W. Ziegelgansberger (1981) Mature spinal ganglion cells are not sensitive to opiate receptor mediated actions. Neurosci. Lett. 21: 211-216. 